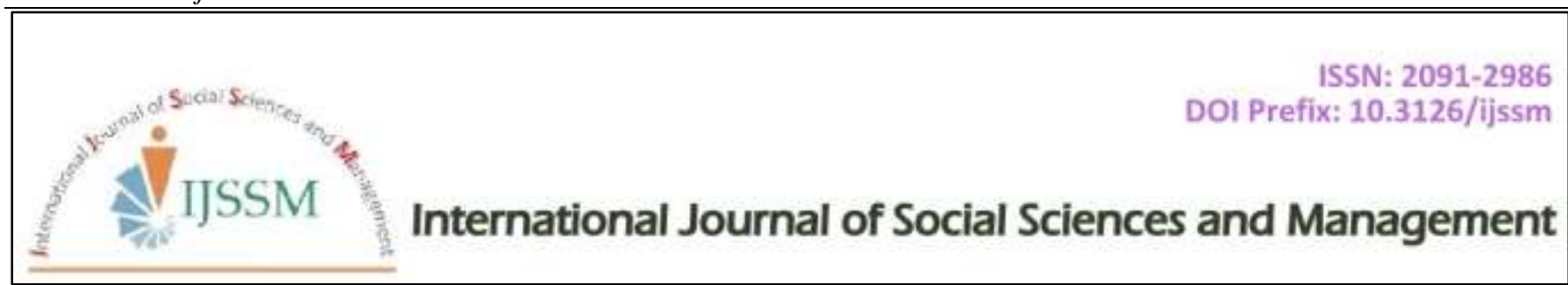

Research Article

\title{
Teachers' Questioning: A Survey of Nepali Schools
}

\author{
Jiban Khadka*
}

Faculty of Social Sciences and Education, Nepal Open University, Lalitpur, Nepal

\begin{tabular}{|c|c|}
\hline Article Information & Abstract \\
\hline $\begin{array}{l}\text { Received: } 24 \text { October } 2020 \\
\text { Revised version received: } 02 \text { January } 2021 \\
\text { Accepted: } 05 \text { January } 2021 \\
\text { Published: } 25 \text { January } 2021 \\
\text { Cite this article as: } \\
\text { J. Khadka (2021) Int. J. Soc. Sc. Manage. } 8(1) \text { : } 333 \text { - } \\
\text { 340. DOI: } 10.3126 / \text { ijssm.v8il.34115 } \\
\text { *Corresponding author } \\
\text { Jiban Khadka, } \\
\text { Faculty of Social Sciences and Education, Nepal } \\
\text { Open University, Lalitpur, Nepal } \\
\text { Email: jiban@ @ou.edu.np } \\
\text { Peer reviewed under authority of IJSSM } \\
\text { (C) } 2021 \text { IJSSM, Permits unrestricted use under the } \\
\text { CC-By-NC license. } \\
\text { OPEN A ACCESS } \\
\text { This is an open access article \& it is licensed under a } \\
\text { Creative Commons Attribution Non-Commercial } 4.0 \\
\text { International } \\
\text { (https://creativecommons.org/licenses/by-nc/4.0/) }\end{array}$ & $\begin{array}{l}\text { This study intends to investigate the present situation of teachers' questioning in } \\
\text { Nepali school, test the use of questions types, and analyze across the characteristics } \\
\text { of the teachers. The data were collected from a survey of } 92 \text { teachers of } 81 \text { schools } \\
\text { including both community and institutional schools. The questionnaire was } \\
\text { prepared largely based on Introduction of Core Skills for Teachers (British Council, } \\
\text { 2016). The Cronbach's alpha was in the range of } 0.7 \text { that ensured the reliability of } \\
\text { the questionnaire. The descriptive statistics and inferential statistics were employed } \\
\text { to find out the results. The results show that in overall study, as the effective } \\
\text { teachers, Nepali school teachers use lower-order questions, higher-order and } \\
\text { follow-up questions in a continuum of frequency from lower to higher order } \\
\text { irrespective of teachers' selected characteristics. However, the teachers with a few } \\
\text { years of experience use lower-order questions, and trained teachers use more } \\
\text { frequently follow-up questions to a significant extent. Based on the findings of this } \\
\text { study, Nepali school policy makers and leaders can adapt the existing teacher } \\
\text { development programs and policies to make effective teaching and learning. } \\
\text { Moreover, teachers can also get insights actually at what level they are in } \\
\text { questioning techniques, and further, improve their questioning techniques. }\end{array}$ \\
\hline Keywords: Questions; Higher-Order; Lower-Orde & bllow-Up; Teachers \\
\hline
\end{tabular}

\section{Introduction}

Student learning achievement is the standard benchmarking of school performance. In support of this statement, Joshi (2017) states that "Best Schools" are known as those schools, which have better academic performance. Academic performance of students is affected by several factors such as students' socio-economic status, parent's education, physical resources, teaching-learning techniques, home related aspects, study habits and backgrounds, classroom practices, teacher characteristics and so on (Mohamed et al., 2018; Olufemi et al., 2018; Farooq et al. 2011; Kim, 2005; Wenglinsky, 2002).
Amongst all, teaching learning activity one of the crucial factors to determine the student learning achievement as the teachers' teaching style is revealed as the significant predictor of students' motivation and learning achievement (Muharam et al., 2019). There are several teaching methods or styles however teachers' questioning is applicable in all types of teaching methods in different extent because of its central importance in the teaching and learning process (Faculty of Education and UQx LEARNx team of contributors, 2018). Teachers' questioning techniques stimulate, mobilize, engage and challenge students, help to 
know their prior knowledge and understanding about the topic of questioning. It focuses on students' thinking on key concepts and issues, and also helps them extend their thinking, promote reasoning, problem solving, evaluation (Faculty of Education and UQx LEARNx team of contributors, 2018)

Further, teachers' questioning technique is an important aspect of effective teaching approach. Considering this, many studies have been conducted, and the studies showed that the students did better as compared to those students who were not asked questions in their teaching and learning activities in a class (as cited in Wilen, 1987, pp. 24-25). Similarly, a qualitative study undertaken by Naz et al. (2013) also revealed the positive association of questioning in the classroom. Over the past century, a number of qualitative, quantitative that include experimental, nonexperimental or case study researches have been conducted on the use of teachers' questioning in the teaching- learning activities in a classroom. However, in Nepali schools, how do the teachers employ questioning in their classroom is under-explored. In this study, despite a number of several influencing factors on the student learning achievement, the researcher has investigated the present status of Nepali school teachers that how frequently they use varieties of questions (lower order, higher order or follow up questions) in their classroom.

\section{Teachers' Questioning in Classroom}

In Nepali schools, teachers generally use two types of teaching methods. They use either teacher-centred or student-centred methods. These methods have been used as per the learning contexts or contents of the subjects. As being the school teacher for many years, I have experienced that the teachers mostly use traditional teaching methods in the schools that is simply teacher-centred. Despite the importance of student centre method, there are several constraints that obstruct to use materials-centred or modern technology-based teaching. However, in either teaching methods, the teachers who use questioning effectively in their classroom, can contribute to better academic performance. Emphasizing the importance of questioning in the classroom, Hilda Taba (1966) says "the single most influential teaching act" (Wilen, 1987).

Literature reports that questioning is used for different purposes in a classroom that eventually enhances the students' overall achievement. Wilen (1987) cites seven reasons for asking students questions to get learners thinking, motivate learners, improve the lesson effectiveness, foster rapport between instructor and learner, enhance learning through communication among learners, assess prior knowledge, assess learning, assess teaching effectiveness, guide learners having difficulties back to the task and encourage personal connections to the content. Similarly, teachers' questions stimulate recall, deepen understanding, develop imagination, and encourage problem solving (Arslan, 2006).

The questioning in the classroom promotes the communication skills of students. They can openly put their opinions, share their understandings. Stating the purposes of teachers' questioning, Cotton (2001) says that questioning is to develop interest and motivate students to become actively involved in the lessons, evaluate students' preparation, develop critical thinking and attitudes, review and summarize, nurture insights, assess achievement of instructional goals and objectives, and stimulate students to pursue knowledge in their own. This is also fact that all types of questions are not suitable all the time. So, different questions can be asked for the effective teaching and learning.

\section{Types of Questions}

The questioning is the most common teaching activity at all grade/levels, but particularly, in elementary schools (Stevens, 1912 as cited in Wilen, 1987). Types of questions a teacher can ask his/her students, has six levels of cognitive domain of Bloom's that can be used to attribute the nature of questions. The six levels of cognitive domain are knowledge, comprehension, application, analysis, synthesis, and evaluation. Out of these six levels, lowerorder questions assess the knowledge and comprehension levels whereas others belong to higher-order questions. Teacher can use different types of questions and different styles of questioning. Naz et al. (2013) illuminate that teachers can pose three types of questions, they are, in hierarchical order, higher-order, low-order and follow-up questions. Wragg and Brown (2003) states two dimensions of questions that the narrow dimension of questions is sometimes described as closed ended questions that includes specific answer whereas broad dimension of questions, also called open ended questions, require a wideranging set of possibilities. Closed/open dimensions of questions are also in convergent/divergent nature of questions (Arslan, 2006). Further, questions can be categorized in various ways. They mention three types of questions. First is conceptual question (eliciting ideas, definitions and reasoning), second is empirical questions requiring answers based on facts or on experimental findings, and the third is value questions which investigate relative worth and merit, moral and environmental issues (Wragg \& Brown, 2003).

From this short review on the variety of questions, the author concluded to study on the three types of questioning for this study. They are higher-order questions, lower-order questions, and follow-up questions. First, two types include all six levels of Bloom's taxonomy of cognitive domain, and the third-follow-up- emphasizes on exploring the in-depth understanding on a topic. 
Higher-Order Questions (HOQs):

In six levels of Bloom's taxonomy, last four levels: Application, analysis, synthesis and evaluation are related to higher-ordered questions (Cotton, 2001). Open ended/divergent questions can also be included under this domain. Naz et al. (2013) illuminate that HOQs cause students to analyze, synthesize or evaluate the material, and their study shows the HOQs are as better way for communication in the classroom. Emphasizing the importance of HOQs, Brualdi (1998) says that HOQs require students to use higher order thinking or reasoning skills. Arslan (2006) highlights on HOQs that divergent or open-ended questions that are more likely to stimulate a discussion and foster an interactive. They use their knowledge to solve, to analyze, and to evaluate, and to assess whether or not a student has truly grasped a concept, and deep understanding of the topic. In the HOQs, teacher can use apply, analyze, assess, assemble, compose, create, examine, explain, examine and the like as action verbs.

\section{Lower-Order Questions (LOQs):}

First two levels of questions (knowledge and understanding) belong to LOQs. LOQs attempt to predict the student's answers before asking the question and have pre-determined answers, and these are procedural or knowledge base questions that address information (Naz et al., 2013; Golkar, 2003). Closed ended/convergent questions also belong to this domain. Arslan (2006) says that LOQs serve the purpose of getting low level cognitive information from students. Cotton (2001) states that teachers ask LOQs that the student merely to recall verbatim, and answer as fact, closed, direct, recall, and knowledge-based information. In this domain, teacher uses name, list, define, match, compare, contrast, add, associate and similar types of action verbs in the questions.

\section{Follow-Up Questions (FUQs):}

The third type of questioning is follow-up questions. This type of questions is posed to explore to get more precise or deeper understanding about a topic. Naz et al. (2013) state the need of FUQs to elicit further explanation and communication, and function to chain together teacher questions and student responses (p. 154). FUQs include both prompting and probing questions. Arslan (2006) states three forms of prompting. First is rephrasing the question in different, perhaps simpler words that relate more closely to the pupil's knowledge and experience. Second is asking a sequence of simple questions that eventually lead back to the original question, and the third is providing a review of information given so far and then asking questions that help the pupil to recall or see the answer (p. 92). On the other hand, probing questions enquire to probe deeper into a topic. Probing questions are most important approach for developing the learner thinking (Arslan, 2006). This type of question may be both higher-order or lower-order type of questions.
Teachers' Characteristics and Questioning in Classroom

How teachers ask question in a classroom is the main concern of this study. As stated in Faculty of Education and UQx LEARNx team of contributors (2018), effective teachers ask higher-order questions, especially, open questions than less effective teachers. Further, they state that questioning depends on the nature and objectives of a lesson to be taught. Then, it is important to keep balance between higher-order and lower-order questions (open and closed questions).

Selection of questions and questioning techniques depend on many factors as teaching and learning is related to cognitive, affective and psychomotor domain of learning. Some studies have focused on the teachers' personal and professional factors as influencing factors on the questioning types and techniques. For examples, teaching English poetry in Nepali context, according to Adhikari (2017) highlights that the number of students in a class, examination, teachers' beliefs, the amount of time available to teach, the availability of resources in the classrooms, workload to teachers, teaching experience of the teachers, and the role of school management are highlighted as the common factors in the selection of teaching methods. Her study showed the difference between trained and untrained teachers in their teaching techniques. Similarly, Islahi and Nasreen (2013) studied on the teachers' as personal characteristics such gender, training, marital status, location of schools whether these factors had influence on the teaching and learning activities, and found insignificant difference on the effectiveness across some characteristics such as gender of teachers.

Level of learning is also an important factor when a teacher ask question to his/her students. It is preferred that a teacher can ask questions as per the student's cognitive development. As stated in McLeod (2018), according to Jean Piaget's (1936) theory of cognitive development, up to basic level of school education, students in the life span of 2 to 11 years belongs to the preoperational to concrete operational stages of cognitive development. In the beginning of basic level classes, they are capable to learn symbolically and gradually through concrete objects or relating to concrete objects. In the age above concrete operational stage (11 year and above), they are no longer in concrete level, they enter formal operational stage, they can learn by reasoning and thinking. The students, in this stage, who mostly belong to the group of secondary level, can learn in abstract way. From this point of view, lowerordered or closed ended questions are more preferred in basic level students, and higher-order or open-ended questions in secondary level students.

From this short review of related literature, there is no uniform results about the teachers' personal and professional characteristics whether they are significant 
while asking questions in their classroom. Then, the researcher concluded to test the following hypothesis:

There is no significant difference on teachers' questioning types across their personal and professional characteristics (gender, level of teaching, teaching subjects, school type and training status).

\section{Research Methods}

Survey research was carried out to investigate the research questions and test the hypothesis of this study. Teachers of secondary and basic level of Nepali school across the country were involved as the respondents in this study. For data collection, a set of questionnaires with two sections was used. In first section, six statements for assessing personal and professional information were managed namely gender of teachers (male and female), level of teaching (basic and secondary), subjects of teaching (Language, Mathematics, Science including Computer Science), types of schools (community and institutional schools) and training status of the teachers (training received and not received). In second section, a set of 16 items/statements were included. This questionnaire was prepared based on Introduction of Core Skills for Teachers (British Council, 2016) and other relevant literature. Permission was taken from to use the questions which were used to assess surface and deep learning. Surface learning is closely related to answering lower-order questions whereas higher-order questions concern with deep learning. Further, Naz et al. (2013), Wilen (1987), Cotton (2001) and Bloom's (1956) literature were the additional sources for developing this Teachers' Questioning Survey Questionnaire (TQSQ) in the study. Out of 16 questions, seven statements were related to higher-order questions, four statements were to lower-order and five statements were follow-up questions. The TQSQ was developed in Likert type scale form that was scaled by 5 points that would assess the frequency of questioning in the classroom. The five pints were distributed as never $=1$, rarely $=2$, sometimes $=3$, frequently $=4$ and always $=5$. The questionnaire was administered through Google Form (docs.google.com) in online mode. The questionnaires were mailed to 120 respondents who were the teachers across the schools of Nepal. The questionnaires were managed in the way that they could not submit without completing all the items. Finally, 92 questionnaires were submitted by the teachers of 81 schools.

The reliability on the data collected through TQSQ was checked by Cronbach's alpha. The data were analyzed using both descriptive and inferential statistics. Before the statistical analysis of the results, normality of the data was checked using skewness and kurtosis, and the homogeneity was tested by Levene's test in respective section. The practice of teachers' questioning types was analyzed using descriptive statistics (mean and standard deviation). The hypotheses were tested using t-test and ANOVA if the assumptions were satisfied for parametric tests, otherwise non-parametric tests were used.

\section{Results and Discussion}

The data were collected from 92 teachers of 81 schools of Nepal including both community and institutional (public and private) schools from 35 districts (geographically 19 Hilly districts, 13 Terai districts and 3 Mountain districts) of all seven states of the country. There was nearly $76 \%$ of return rate of the questionnaire. As there were not missing responses and cases, all 92 questionnaires were used for analysis. Regarding the nature of data, male teachers had the dominant role as the percentage of male teachers was $83.7 \%$ (77) whereas only 15 female teachers (16.3\%) participated in responding the questionnaires. Out of them, 82 teachers were of secondary and only 10 teachers from basic level. Likewise, 49 teachers teaching language (Nepali and English), 10 Mathematics, 9 Science including Computer Science, and 24 Social Studies and others were involved. 62 teachers from public schools and 30 from private schools took part in responding the questionnaire. There was a majority of teachers $(82,91.3 \%)$ had the experience of more than five years and had the training $(80$, $97 \%)$.

After editing and cleaning the date, for examining the reliability of the questionnaire, Cronbach's alpha was used to examine its internal consistency. SPSS was used to compute the statistical results, and the values of Cronbach's alpha for three major components: Higher-ordered Questions (HOQs), Lower-order Questions (LOQs) and Follow-Up Questions (FUQs) are presented in Table 1.

Table 1: Cronbach's alpha Values for Internal Consistency

\begin{tabular}{ll}
\hline Variables & Cronbach's alpha \\
\hline Higher-ordered Question (HOQs) & 0.711 \\
Lower-order Questions (LOQs) & 0.690 \\
Follow-Up Questions (FUQs) & 0.709 \\
\hline
\end{tabular}

The values of Cronbach's alpha presented in Table 1 are 0.711, 0.690 and 0.709 on HOQs, LOQs and FUQ respectively. The range of Cronbach's alpha is in the range of 0.7 , as stated by Sekaran (2003), the values ensure the internal consistency of the questionnaire in each type of the questions.

For testing the normality, as stated in the methods section, skewness and kurtosis are used. The values of skewness and kurtosis of HOQs, LOQs and FUQs are as shown in the Table 2 .

For the analysis of statistics of skewness and kurtosis, the values of both skewness and kurtosis are in the range of 0.410 to 0.110 . As stated by Verma and Abdel (2019), the 
statistical values of skewness and Kurtosis lie in the interval of -1 and +1 , so the distribution of the data is normally distributed. This permits to use parametric tests for the testing hypotheses.

The mean and standard deviation (sd) are used to analyze the frequency level of asking three types of questions. As aforementioned, five-point Likert scale was used in the questionnaire. For specifying the scales, as stated by Polit and Hungler (1997), the three categories were 1.00-2.33, 2.34-3.67 and 3.68-5 in the interval of 1.33, and the categories would represent 'almost rarely', 'sometimes', and 'almost always' respectively. The values of mean and sds of the variables are presented in the Table 3.

For the three types of questions (LOQs, HOQs and FUQs), the mean values lie in the interval of 3.68 to 5 . These values indicate the category 'almost always' which means that the teachers most often use varieties of questions in their classes. As the value of FUQs is highest, they more often use probing or follow up questions in their classes. The values of SD $(0.587,0.535 \& 0.595)$ indicate low level of variability of scores as they are below 1 if -1 sd is assumed as cut-off point that show the greater representativeness of the mean values.

In a nutshell, as perceived by the school teachers, based on the frequencies of the use of questioning types, the teachers mostly use follow-up question at highest frequency, then followed by higher-order questions, and lower-order questions at minimum level.

The hypothesis of this study was to test on whether there is significant difference on the use of three varieties of questions (LOQs, HOQs and FUQs) across the personal and professional characteristics of the teachers (gender, teaching level, subjects of teaching, school type, and training status). For five categorical variables: gender, teaching level, school type, and training status, t-test was used to test the significant difference as the variables had two levels and for the rest (subjects of teaching), ANOVA was employed.

Table 2: Statistics of Skewness and Kurtosis for Normality Test

\begin{tabular}{lcccccc}
\hline & $\mathbf{N}$ & Maximum & \multicolumn{2}{c}{ Skewness } & \multicolumn{2}{c}{ Kurtosis } \\
& Statistics & Statistics & Statistics & Std. Error & Statistics & Std. Error \\
\hline Lower Order Questions & 92 & 5.00 & 0.110 & 0.251 & -0.356 & 0.498 \\
Higher Order Questions & 92 & 5.00 & -0.374 & 0.251 & 0.088 & 0.498 \\
Follow Up Questions & 92 & 5.00 & -0.419 & 0.251 & -0.105 & 0.498 \\
Valid N (listwise) & 92 & & & & & \\
\hline
\end{tabular}

Table 3: Descriptive Statistics for the use of LOQs, HOQs and FUQs

\begin{tabular}{lccc}
\hline $\begin{array}{l}\text { Questions and Questioning } \\
\text { related to Statements }\end{array}$ & N & Mean & Std. Deviation \\
\hline Lower Order Questions (LOQs) & 92 & 3.76 & .587 \\
Higher Order Questions (HOQs) & 92 & 3.86 & .535 \\
Follow Up Questions (FUQs) & 92 & 3.98 & .595 \\
Valid N (listwise) & 92 & & \\
\hline
\end{tabular}

Table 4: Independent Samples Test on Gender of Teachers

Levene's Test for

Equality of Variances$$
\text { F }
$$

t-test for Equality of Means

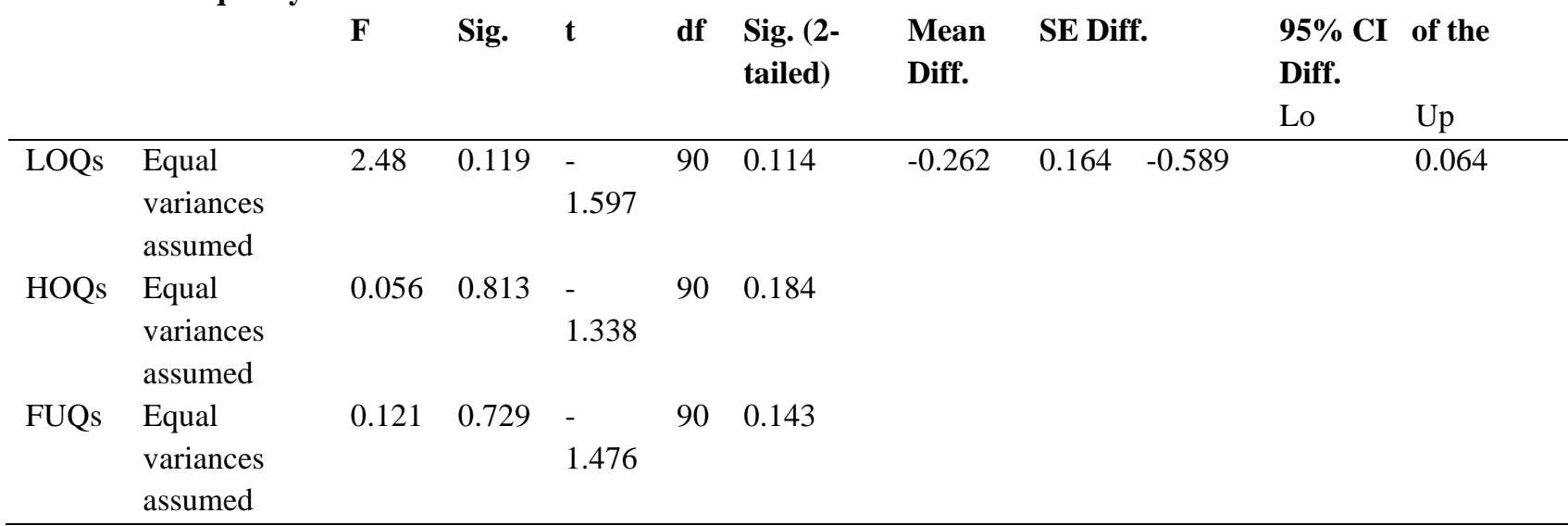


As the Levene's test values ( $\mathrm{p}$-values $=0.119,0.813 \&$ 0.729 ) are more than $5 \%$ level of significance. This result shows that the variances are assumed to be equal. Then, $\mathrm{t}-$ test value ( $\mathrm{p}$-values $=0.114,0.184 \& 0.143$ ) are more than $5 \%$ level of significance. This shows that the use of LOQs, HOQs and FUQs are not significantly different across the gender of teachers. This finding is in line with the study of Islahi and Nasreen (2013) which showed in overall observation, male teachers' questioning type was not significantly different from the female teachers. In conclusion, In Nepali context, the mean values presented in table $(3.76,3.86 \& 3.98)$ indicate that irrespective of gender, teachers often ask three types of questions (LOQs, HOQs \& FUQs) in their classes.

Similarly, across the level of teaching, school type, teaching experience and training status, in the case of level of teaching, from t-test, the p-values on LOQs, HOQs and FUQs are $0.837,0.127$ and 0.264 , in school type, p-values are $0.417,0.327$ and 0.550 , in teaching experience, the $\mathrm{p}$ values are $0.032,0.108$ and 0.144 , and in training status, the p-values are 0.860, 0.078 and 0.036. As all p-values are more than $5 \%$ level of significance, all the results are insignificant except LOQs across teaching experience and FOQs across training status.

Regarding the types of schools, this finding shows that the teachers are not different in the use of all types of questions. This surprising finding may raise the questions that both types of schools (public and private schools) have the same nature of teachers or have equal performance. However, it contradicts to the study of Mathema and Bista (2006) that the private schools have better academic performance.

Across two levels of teaching experience (5 years or less than and more than 5 years), the respective mean values on LOQs (lower-ordered questions) are 4.18 and 3.72. The mean values show that the teachers with experience up to 5 years more frequently use the lower-ordered question as compared to others. However, the teachers with up to 5 years of experience were not identified whether they were from basic or secondary level. This finding seems contradicted to Jain (2014) that the teacher effectiveness was independent of teaching experience. This is also supported by the study of Mathema and Bista (2006) that the teachers with long experience were not found effective in terms of students' performance. However, in this study, the mean values lie in the same interval of 3.68 to 5 that do not show any more difference in the use of questioning types.

Considering the level of teaching, teachers of both basic and secondary level, the use of LOQs, HOQs and FUQs are in similar order as there is no significant difference on each type of questions. This finding contradicts to the notion of Piaget's theory of cognitive development (McLeod, 2018). By this notion, teachers are expected to use lower-order question in elementary classes, and then gradually use higher-order questions in upper classes. Regarding the training status of teachers, the use of FOQs (follow-up questions) across training status of the teacher is significantly different. The mean value $(=4.04)$ for the teachers who had received training is more than the mean value $(=3.55)$ for the teachers who had not received the training. However, both values fall in the same interval of the frequency of asking Follow-Up questions. The finding is supported by the previous studies. For examples, Islahi and Nasreen (2013) have revealed that trained teachers were more effective as compared to untrained teachers. This is also supported by the study of Regmi (2015) that shows trained teachers were more effective in use of teaching techniques such as asking higher-order questions, openended questions, and comprehension questions as compared to untrained teachers.

Another hypothesis of this study was tested by ANOVA that tested on the types of questions across the teachers' subject groups. The result is presented in Table 5.

Table 5: ANOVA on Question Type across Subject Groups of Teachers

\begin{tabular}{lllllll}
\hline Question Type & & Sum of Squares & df & Mean Square & F & Sig. \\
\hline Lower Order Questions & Between Groups & .328 & 3 & 0.109 & 0.310 & 0.818 \\
& Within Groups & 31.0 & 88 & 0.353 & & \\
& Total & 31.4 & 91 & & 0.501 & 0.683 \\
Higher Order Questions & Between Groups & 0.438 & 3 & 0.146 & & \\
& Within Groups & 25.6 & 88 & 0.292 & & \\
& Total & 26.1 & 91 & & 0.374 \\
\multirow{2}{*}{ Follow Up Questions } & Between Groups & 1.11 & 3 & 0.372 & & \\
& Within Groups & 31.1 & 88 & 0.354 & & \\
\hline
\end{tabular}


The result of ANOVA (table 5) shows that the p-values $(=0.818,0.683 \& 0.374)$ of LOQs, HOQs and FUQs are more than level of significance $(5 \%=0.05)$. Then, the teachers are not significantly different in using three types of questions across their subject groups (Language, Mathematics, Science including Computer Science \& Social Studies and others). In relation to this finding, some qualitative studies have showed the mixed results. For examples, Dahal (2019) found that mathematics teachers ask more questions within the simple to complex level with focusing on lower-order question. Astrid et al.'s (2019) study on English teachers showed that teachers use convergent, divergent, and procedural questions although they use convergent questions more frequently. Likewise, Nisa and Khan (2012) found from the study of Social Studies teachers that most of the teacher's questions were lower-order. In overall explanation, most of the different subject teachers use all types of questions but they usually ask lower-order questions as similar to the finding of this study.

\section{Conclusion}

Teachers' questioning is crucial in teaching and learning as it is important for all-round development of a child. In overall study, as the effective teachers, Nepali school teachers use lower-order, higher-order and follow-up questions in a continuum of frequency from lower to higher order irrespective of gender, teaching level and subjects, experience, school type and training status. However, the teachers with a few years of experience use lower-order questions, and trained teachers use more frequently followup questions in low level of significant extent. Despite the significant difference, in counterpart, teachers with many years of experience use lower-order questions, and untrained teachers use follow-up questions in the same range of frequency. The teachers of public schools use effective way of questioning in the classroom however the evidences show that the public schools have no good academic performance as compared to private schools. Based on the findings of this study, Nepali school policy makers and leaders can adapt the existing teacher development programs and policies to make effective teaching and learning. Moreover, teachers can also get insights actually at what level they are in questioning techniques, and further, improve their classroom instruction through effective questioning techniques. However, to substantiate this finding, in both types of schools (Public and Private Schools), these questioning types can be reexamined by taking a large sample size of teachers, multiple methods of research in connection to the performance in future.

\section{References}

Adhikari K (2017) Factors influencing the selection of teaching methods in an EFL context (Master Thesis). Michigan State University.
Arslan M (2006) The role of questioning in the classroom. Hasan Ali Yucel Egitim Fakultesi Dergisi Sayı 2: 81-103.

Astrid A, Amrina RD, Desvitasari, D, Fitriani, U and Shahab, A (2019) The power of questioning: Teacher's questioning strategies in the EFL classrooms. International Journal in Education 3 (1).

Bloom BS (Ed.) (1956) Taxonomy of educational objectives. USA: David McKay Company, Inc.

British Council (2016) Introduction to core skills training for teachers and leaders. UK: Author

Brualdi AC (1998) Classroom questions. ERIC/AE Digest. ERIC Clearinghouse on Assessment and Evaluation Washington $D C$. Retrieved from https://eric.ed.gov/

Cotton K (2001) Classroom questioning. School improvement research series 3. Retrieved from http://www.sciepub.com/reference/174028.

Dahal N (2019) Understanding the use of questioning by mathematics teachers: A revelation. International Journal of Innovation, Creativity and Change 5(1).

Faculty of Education and UQx LEARNx team of contributors (2018) Questioning. In: Lombardi P (Ed.), Instructional Methods, Strategies and Technologies to Meet the Needs of All Learners UK: Creative Commons Attribution-NonCommercial-Share Alike CC BY-NC-SA 4.0. Retrieved from

https://granite.pressbooks.pub/teachingdiverselearners/. $161-172$

Farooq MS, Chaudhry AH, Shafiq M and Berhanu G (2011) Factors affecting students' quality of academic performance: A case of secondary school level. Journal of Quality and Technology Management 7(2): 1-14.

Golkar M (2003) Classroom observation: Interaction time and question and answer patterns. Indian Journal of Applied Linguistics 29:79-89.

Islahi F and Nasreen (2013) Who make effective teachers, men or women? An Indian perspective. Universal Journal of Educational Research 1(4): 285-293. DOI: 10.13189/ujer.2013.010402.

Jain A (2014) Effect of students' feedback and teaching experience on teacher effectiveness of secondary school teachers. Learning Community 5(1): 79-91. DOI: 10.5958/2231458X.2014.00472.2.

Joshi P (2017) Identifying and investigating the "Best" schools: A network-based analysis on Nepal's public education system. A Journal of Comparative and International Education, 1-27.

Kim JS (2005) The effects of the constructivist teaching approach on student academic achievement, self-concept, and learning strategies. Asia Pacific Education Review 6(1): 7 19. doi: $10.1007 / \mathrm{BF} 03024963$

Mathema KB and Bista, MB (2006) Study on student performance in SLC. Kathmandu: Ministry of Education and Sports.

McLeod SA (2018) Jean Piaget's theory of cognitive development. Retrieved from https://www.simplypsychology.org/piaget.html.

Mohamed AA, Mohamud Dahie A and Warsame AA (2018) Factors affecting student academic performance: Case study from University of Somalia in Mogadishu-Somalia. IOSR Journal of Humanities and Social Science 23(3): 7380 . 
Muharam LO, Ihjon I, Hijrah WO and Samiruddin T (2019) The effect of teaching style on students' motivation and academic achievement: Empirical evidence from public senior high school in Konawe Selatan Regency. International Journal of Scientific \& Technology Research Volume 8(09).

Naz A, Khan W and Daraz U (2013) Teacher's questioning effects on students communication in classroom performance. Journal of Education and Practice 4 (7).

Nisa S and Khan AA (2012) Questioning practices in a social studies classroom: A case study from Pakistan. International J. Soc. Sci. \& Education 2 (3).

Olufemi OT, Adediran, AA and Oyediran, WO (2018) Factors affecting students' academic performance in colleges of education in Southwest, Nigeria. British Journal of Education 6 (10): 43-56.

Polit DF and Hungler BP (1997) Essentials of nursing research: Methods, appraisals and utilization (4th ed.). Philadelphia: Lippincott-Raven Publishers.
Regmi CR (2015) Techniques used by trained and untrained teachers in teaching poetry (Master's Thesis). Tribhuvan University, Faculty of Education, Nepal.

Sekaran U (2003) Research methods for business: A skill building approach (4th ed.). USA: John Wiley \& Sons.

Verma JP and Abdel-Salam AG (2019) Testing statistical assumptions in research. USA: John Wiley \& Sons, Inc.

Wenglinsky H (2002) How schools matter: The link between teacher classroom practices and student academic performance. Education Policy Analysis Archives 10(12). Retrieved from http://www.indiana.edu/ educy520/sec6342/week_07/we nglinsky02.pdf

Wilen WW (Ed.) (1987) Questions, questioning techniques, and effective teaching. National Education Association, Washington, D. C. Retrieved from https://eric.ed.gov/?id=ED310102

Wragg EC and Brown G (2003) Questioning in the secondary school. NY: Taylor \& Francis e-Library. 